\title{
CADASIL: A Monogenic Condition Causing Stroke and Subcortical Vascular Dementia
}

\author{
Martin Dichgans \\ Department of Neurology, Klinikum Grosshadern, Ludwig Maximilians University, Munich, Germany
}

\author{
Key Words \\ Cerebrovascular disease $\cdot$ Stroke $\cdot$ Dementia . \\ Small vessel disease $\cdot$ CADASIL $\cdot$ Notch3
}

\begin{abstract}
Mutations in Notch3 are the cause of cerebral autosomal dominant arteriopathy with subcortical infarcts and leukoencephalopathy (CADASIL), an inherited small vessel disease leading to subcortical strokes and vascular dementia. The phenotypic presentation is variable but remarkable for a high frequency of migraine with aura. Magnetic resonance images show a microangiopathic pattern of lesions. Prominent involvement of the temporopolar white matter and involvement of the temporopolar arcuate fibers are conspicuous findings seen in many patients. The underlying angiopathy is characterized by a unique type of ultrastructural basal lamina deposits and by degeneration of vascular smooth muscle cells which are the major source of Notch3 expression. In line with these findings there is evidence for a functional impairment of vascular smooth muscle cells. CADASIL has opened a new perspective in studying basic mechanisms of vessel wall degeneration and ischemic tissue damage related to small vessel disease.
\end{abstract}

Copyright $(C 2002$ S. Karger AG, Base

\section{Introduction}

In 1977, Sourander and Walinder [1] presented clinical and pathological findings on 5 nonhypertensive patients who had experienced recurrent ischemic strokes with onset before age 40. Four of them developed progressive dementia. Post-mortem studies revealed multiple small infarcts and diffuse white matter changes as well as vascular alterations most prominent in small muscular arteries. Because of multiple affected family members in three successive generations the authors suspected an autosomal dominant mode of transmission. Subsequently, additional families with similar clinical and pathological findings were described [2-7]. A major breakthrough was achieved in 1993, when Tournier-Lasserve et al. [8] mapped the disease gene locus to chromosome 19 using a positional cloning approach. Since then, CADASIL (cerebral autosomal dominant arteriopathy with subcortical infarcts and leukoencephalopathy) has become the accepted acronym for the condition. Moreover, the number of families identified increased dramatically (several hundred in a few years). Narrowing of the disease gene locus $[9,10]$ eventually led to the identification of the responsible gene as Notch3 [11]. It further became clear that expression of Notch3 is strongly restricted to vascular smooth muscle cells (VSMC) - a key element in small vessel pathology

\begin{tabular}{ll}
\hline KARGER & ( ) 2002 S. Karger AG, Basel \\
1015-9770/02/0136-0037\$18.50/0 \\
$\begin{array}{l}\text { Fax +41 61306 1234 } \\
\begin{array}{l}\text { E-Mail karger@karger.ch } \\
\text { www.karger.com }\end{array}\end{array}$ & $\begin{array}{l}\text { Accessible online at: } \\
\text { www.karger.com/journals/ced }\end{array}$
\end{tabular}

PD Dr. med. Martin Dichgans

Department of Neurology, Klinikum Grosshadern

Marchioninistrasse 15, D-81377 Munich (Germany)

Tel. +49 897095 3674, Fax +49 8970953677

E-Mailmdichgans@nefo.med.uni-muenchen.de 
[12]. This has opened an entire avenue for studying the mechanisms of vessel wall degeneration and microangiopathy-related cerebral damage.

\section{Clinical Phenotype}

In most cases, CADASIL patients present with one of the following four manifestations: ischemic episodes, cognitive deficits, migraine with aura and psychiatric disturbance.

Ischemic episodes (TIA or stroke) are the most frequent presentation found in about $85 \%$ of symptomatic individuals [13-15]. Mean age at onset for ischemic episodes is around 46 years with a range of about 30-70 years. In many cases they present as a classic lacunar syndrome (pure motor stroke, ataxic hemiparesis, dysarthria - clumsy hand syndrome, pure sensory stroke, sensorimotor stroke) but other ischemic syndromes (brainstem or hemispheric) are also observed. They are often recurrent leading to severe disability with gait disturbance, urinary incontinence and pseudobulbar palsy. Strokes involving the territory of a large artery have occasionally been reported [16]. However, such observations may be coincidental. Without doubt, strokes related to small vessel pathology are the main manifestation of the disease.

Cognitive deficits are the second most frequent feature observed in about $60 \%$ of symptomatic individuals. By the age of 65 years, two thirds of the patients have become demented [13]. Cognitive impairment includes deficits in episodic memory, attention, executive and visuospatial functions, usually accompanied by psychomotor slowing and a narrowing of the field of interest. In most cases, cognitive decline is slowly progressive with additional stepwise deterioration.

Migraine with aura is among the early manifestations of CADASIL and is found in about $30 \%$ of patients. Aura symptoms tend to prefer the visual and sensory system. However, in a considerable number of cases, symptoms are those of hemiplegic migraine, basilar migraine or isolated aura which may be difficult to differentiate from ischemic episodes. In fact, the relationship between 'migraine with aura' and 'TIA with headache' is an important pathophysiologic aspect of the disease. In an individual patient the type of aura may vary or be invariantly the same. In most patients who develop migraine, it is the first symptom (onset usually before age 40 years). Also, the frequency of migraine attacks seems to decrease after the first stroke [13].
Mood disorders are the most frequent psychiatric manifestations and occur in about 30\% of the cases. Apart from adjustment disorders, patients may develop severe major depression. Other manifestations include manicdepressive disorder, panic disorder, hallucinatory syndromes and delusional episodes. Five to $10 \%$ of the CADASIL patients develop epileptic seizures which may require treatment. There have been single reports on spinal cord signs [17] or infarcts [1, 18] as well as intracerebral hemorrhages $[1,19]$. However, these are single observations.

The overall course of CADASIL is highly variable, even within single families. Some patients remain asymptomatic until their 70s whereas others are severely disabled by the age of 50. Early onset does not necessarily predict rapid progression. In a large population of patients the duration from onset to death varied between 3 and 43 (mean 23) years [13]. Advanced stages correspond to the clinical syndrome of severe Binswanger's encephalopathy [20]. Mean age at death is about 60 years [1315].

\section{Neuroimaging}

MRI reveals two major types of abnormalities, the first being sharply demarcated regions that are isointense to CSF on T1- and T2-weighted images. Many of these lesions are suggestive of lacunar infarcts regarding size, shape and location (basal ganglia, thalamus, internal capsule and brainstem, in particular pons). The second type of abnormality consists of less well-demarcated T2-hyperintensities of variable size that may show different degrees of hypointensity on T1-weighted images but are clearly distinct from CSF. The majority of these lesions are located in the subcortical white matter. However, similar lesions may also be seen in other brain regions including the subcortical gray matter [21, 22]. Small irregular T2 hyperintensities of the periventricular and deep white matter are usually the first sign seen in younger individuals. As individuals get older, lesions tend to become confluent eventually affecting a large proportion of the white matter. In addition, patchy areas of variable T1-signal hypointensity become apparent within confluent lesions, indicating progressive tissue damage within T2-visible lesions. Apparently, the onset of MRI visible lesions and the rate of progression show considerable variation [14, 23 ], even though by about age 35 years all gene carriers have developed lesions on MRI [14]. The pattern of MRI lesions [21, 24] shares many similarities with sporadic

\footnotetext{
$\overline{38} \quad \overline{\text { Cerebrovasc Dis 2002;13(suppl 2):37-41 }}$
} 
small vessel disease. However, there are two important signs that have turned out to be particularly helpful in the identification of disease gene carriers: (i) T2-signal hyperintensities within the temporopolar white matter [22, 25], and (ii) involvement of the subcortical U-fibers within temporopolar and superior frontal regions [22]. In conjunction with the clinical data (including family history and risk factors) those features may help in selecting patients for specific diagnostic tests (see below). Conventional angiography is not helpful. Moreover, CADASIL patients are at an increased risk of developing angiographic complications [26].

Studies on brain perfusion and brain metabolism found reductions of cerebral blood flow, cerebral blood volume and cerebral glucose utilization [27-31]. These findings are in agreement with chronic ischemia, likely to play a prominent role in the development of CADASIL lesions. Moreover, two recent studies found marked impairment of cerebral vasoreactivity [27, 28] consistent with the degeneration of VSMC in small arteries and arterioles. Also, the arterio-venous cerebral transit time was found to be markedly prolonged in CADASIL patients compared to controls [42].

Using different approaches such as magnetic resonance spectroscopy [32], diffusion tensor imaging [33] and magnetization transfer imaging [34], recent studies have provided converging evidence for subtle tissue alterations outside T2-visible lesions both in the white and gray matter including cortex. Moreover, these studies indicate various degrees of tissue damage (demyelination, axonal loss, gliosis, enlargement of the extracellular spaces) in T2 lesions. Quite importantly, both the total volume of lesions $[23,34]$ and the extent of signal alterations within lesions [32-34] were shown to correlate with clinical parameters, indicating that these metrics might be used as outcome measures in future therapeutic trials.

\section{Pathology}

Most autopsy studies have been carried out on patients with advanced disease. In such cases, macroscopic examination of the brain reveals a pronounced rarefaction of the subcortical white matter with periventricular preference [35]. Other consistent findings are lacunar infarcts located predominantly within the basal ganglia, thalamus and brainstem (in particular the pons). Histopathological examination shows various degrees of demyelination, axonal loss, enlargement of the extracellular space and mild astrocytic gliosis compatible with chronic ischemia. The underlying vascular lesion is a unique nonarteriosclerotic, amyloid-negative angiopathy involving small arteries $(100-400 \mu \mathrm{m})$ and capillaries primarily in the brain but also in other organs. The diagnosis may therefore be established by a simple skin biopsy [43]. Ultrastructural examination reveals characteristic granular osmiophilic deposits within the vascular basal lamina which are considered diagnostic. These deposits are often seen in direct contact with VSMC which degenerate and eventually disappear. Yet they have not been characterized biochemically and their origin remains unresolved. Even though CADASIL is a generalized angiopathy, vascular complications appear to be limited to the brain. This discrepancy might in part be related to the predominant involvement of leptomeningeal and long penetrating arteries of the brain. However, additional factors such as properties of the blood-brain barrier may be suspected [35, 36].

\section{The Molecular Basis of CADASIL}

CADASIL patients carry mutations in the Notch 3 gene which is one of four known homologues of Drosophila Notch [11, 37]. Like all Notch genes, Notch 3 codes for a large single-pass transmembrane receptor. The Notch signaling pathway has been shown to be essential for embryonic development in vertebrates and invertebrates. By interaction with their extracellular ligands, Notch receptors mediate cell-cell interactions that specify cell fate decisions during development [38].

A constant feature of Notch receptors is a large number of tandemly arranged epidermal growth factor-like (EGFlike) repeat domains which account for most of the extracellular domains of these proteins. All CADASIL mutations are located in EGF-like repeat domains of the Notch3 receptor with a strong cluster at the $\mathrm{N}$-terminus $[39,40]$. Mutations show a strikingly stereotyped nature: all mutations lead to the gain or loss of an uneven number of cysteine residues [39-41]. Since each wtEGF repeat domain contains six cysteines, these mutations result in an odd number of cysteine residues within one EGF domain. It has been suggested that the unpaired cysteine residue generated by the mutations could cause aberrant interactions of Notch 3 with other Notch 3 molecules or other proteins, and in fact, recent data have provided evidence for multimerization of mutant Notch3 [12].

The expression of Notch 3 is restricted to VSMC in human adult tissues. In CADASIL there is an excessive accumulation of the ectodomain of the Notch3 receptor within blood vessels [12]. Accumulation takes place at the 
cytoplasmic membrane of VSMC and pericytes, in close vicinity to but not within the granular osmiophilic deposits. These findings underline the central role of VSMC pathology in CADASIL, in line with functional investigations evidencing VSMC dysfunction in vivo [28].

\section{Conclusion}

CADASIL has been recognized as a surprisingly frequent condition. The responsible genetic defect has been identified and the pivotal role of VSMC has been firmly established. A number of challenging questions remain: (i) What are the mechanisms leading to Notch3 receptor aggregation? (ii) What causes VSMC to degenerate? (iii) What are the molecular components contained within the granular deposits? (iv) How are the sequences of events that eventually cause lacunar infarcts and diffuse tissue alterations visible at autopsy? Some of these questions may be answered in appropriate animal models.

Little is known about the mechanisms underlying migraine in CADASIL. Studies on the pathophysiology of migraine in CADASIL may provide important insights into the more common aspects of migraine, in particular migraine with aura. Other important issues include the determinants of subcortical vascular dementia, and the identification of factors influencing disease progression. Obviously the greatest challenge will be to identify an effective treatment for this frequently devastating condition.

\section{References}

1 Sourander P, Walinder J: Hereditary multiinfarct dementia. Morphological and clinical studies of a new disease. Acta Neuropathol 1977;39:247-254

2 Stevens DL, Hewlett RH, Brownell B: Chronic familial vascular encephalopathy. Lancet 1977 ; i:1364-1365.

3 Sonninen V, Savontaus ML: Hereditary multiinfarct dementia. Eur Neurol 1987;27:209_ 215.

4 Davous P, Fallet-Bianco C: Familial subcortical dementia with arteriopathic leukoencephalopathy. A clinico-pathological case. Rev Neurol 1991;147:376-384

5 Tournier-Lasserve E, Iba-Zizen MT, Romero N, Bousser MG: Autosomal dominant syndrome with stroke-like episodes and leukoencephalopathy. Stroke 1991;22:1297-1302.

6 Mas JL, Dilouya A, de Recondo J: A familial disorder with subcortical ischemic strokes, dementia, and leukoencephalopathy. Neurology 1992;42:1015-1019.

7 Colmant HJ: Familiäre zerebrale Gefässerkrankung. Zentralbl Allg Pathol 1980;124:163.

8 Tournier-Lasserve E, Joutel A, Melki J, Weissenbach J, Lathrop GM, Chabriat $\mathrm{H}$, et al: Cerebral autosomal dominant arteriopathy with subcortical infarcts and leukoencephalopathy maps to chromosome $19 \mathrm{q} 12$. Nat Genet 1993;3:256-259.

9 Dichgans M, Mayer M, Muller-Myhsok B, Straube A, Gasser T: Identification of a key recombinant narrows the CADASIL gene region to $8 \mathrm{cM}$ and argues against allelism of CADASIL and familial hemiplegic migraine. Genomics 1996;32:151-154.
10 Ducros A, Nagy T, Alamowitch S, Nibbio A, Joutel A, Vahedi K, et al: Cerebral autosomal dominant arteriopathy with subcortical infarcts and leukoencephalopathy, genetic homogeneity, and mapping of the locus within a 2cM interval. Am J Hum Genet 1996;58:171181.

11 Joutel A, Corpechot C, Ducros A, Vahedi K, Chabriat H, Mouton P, et al: Notch3 mutations in CADASIL, a hereditary adult-onset condition causing stroke and dementia. Nature 1996;383:707-710.

12 Joutel A, Andreux F, Gaulis S, Domenga V, Cecillon M, Battail N, et al: The ectodomain of Notch3 receptor accumulates within the cerebrovasculature of CADASIL patients. J Clin Invest 2000; 105:597-605.

13 Dichgans M, Mayer M, Uttner I, Bruning R, Muller-Hocker J, Rungger G, et al: The phenotypic spectrum of CADASIL: Clinical findings in 102 cases. Ann Neurol 1998;44:731-739.

14 Chabriat H, Vahedi K, Iba-Zizen MT, Joutel A, Nibbio A, Nagy TG, et al: Clinical spectrum of CADASIL: A study of seven families. Cerebral autosomal dominant arteriopathy with subcortical infarcts and leukoencephalopathy. Lancet 1995;346:934-939.

15 Desmond DW, Moroney JT, Lynch T, Chan S, Chin SS, Mohr JP: The natural history of CADASIL: A pooled analysis of previously published cases. Stroke 1999;30:1230-1233.

16 Rubio A, Rifkin D, Powers JM, Patel U, Stewart J, Faust $\mathrm{P}$, et al: Phenotypic variability of CADASIL and novel morphologic findings. Acta Neuropathol 1997;94:247-254.

17 Hutchinson M, O'Riordan J, Javed M, Quin E, Macerlaine D, Wilcox T, et al: Familial hemiplegic migraine and autosomal dominant arteriopathy with leukoencephalopathy (CADASIL). Ann Neurol 1995;38:817-824.
18 Gutierrez-Molina M, Caminero RA, Martinez GC, Arpa GJ, Morales BC, Amer G: Small arterial granular degeneration in familial Binswanger's syndrome. Acta Neuropathol 1994;87:98-105.

19 Baudrimont M, Dubas F, Joutel A, TournierLasserve E, Bousser MG: Autosomal dominant leukoencephalopathy and subcortical ischemic stroke. A clinicopathological study. Stroke 1993;24:122-125.

20 Caplan LR: Binswanger's disease-revisited. Neurology 1995;45:626-633.

21 Chabriat H, Levy C, Taillia H, Iba-Zizen MT, Vahedi K, Joutel A, et al: Patterns of MRI lesions in CADASIL. Neurology 1998;51:452457.

22 Auer DP, Putz B, Gossl C, Elbel GK, Gasser T, Dichgans M: Differential lesion patterns in CADASIL and sporadic subcortical arteriosclerotic encephalopathy: MR imaging study with statistical parametric group comparison. Radiology 2001;218:443-451.

23 Dichgans M, Filippi M, Bruning R, Iannucci G, Berchtenbreiter C, Minicucci L, et al: Quantitative MRI in CADASIL: Correlation with disability and cognitive performance. Neurology 1999;52:1361-1367.

24 Yousry TA, Seelos K, Mayer M, Bruning R, Uttner I, Dichgans M, et al: Characteristic MR lesion pattern and correlation of $\mathrm{T} 1$ and $\mathrm{T} 2$ lesion volume with neurologic and neuropsychological findings in cerebral autosomal dominant arteriopathy with subcortical infarcts and leukoencephalopathy (CADASIL). AJNR Am J Neuroradiol 1999;20:91-100.

25 O’Sullivan M, Jarosz JM, Martin RJ, Deasy N, Powell JF, Markus HS: MRI hyperintensities of the temporal lobe and external capsule in patients with CADASIL. Neurology 2001;56: 628-634. 
26 Dichgans M, Petersen D: Angiographic complications in CADASIL. Lancet 1997;349:776777.

27 Chabriat H, Pappata S, Ostergaard L, Clark CA, Pachot-Clouard M, Vahedi K, et al: Cerebral hemodynamics in CADASIL before and after acetazolamide challenge assessed with MRI bolus tracking. Stroke 2000;31:19041912.

28 Pfefferkorn T, von Stuckrad-Barre S, Herzog J, Gasser T, Hamann G, Dichgans M: Reduced cerebrovascular $\mathrm{CO}_{2}$ reactivity in CADASIL: A transcranial Doppler sonography study. Stroke 2001;32:17-21.

29 Brüning R, Dichgans M, Berchtenbreiter C, Yousry TA, Seelos K, Wu RH, et al: CADASIL: Decrease in regional cerebral blood volume in hyperintense subcortical lesions inversely correlates with disability and cognitive performance. AJNR Am J Neuroradiol 2001;22: 1268-1274.

30 Chabriat H, Bousser MG, Pappata S: Cerebral autosomal dominant arteriopathy with subcortical infarcts and leukoencephalopathy: A positron emission tomography study in two affected family members. Stroke 1995;26:1729_ 1730 .
31 Mellies JK, Baumer T, Muller JA, TournierLasserve $\mathrm{E}$, Chabriat $\mathrm{H}$, Knobloch $\mathrm{O}$, et al: SPECT study of a German CADASIL family: A phenotype with migraine and progressive dementia only. Neurology 1998;50:17151721.

32 Auer D, Schirmer T, Heidenreich JO, Herzog J, Pütz B, Dichgans M: Altered white and gray matter metabolism in CADASIL as detected by chemical shift imaging and single voxel ${ }^{1} \mathrm{H}$ MRS. Neurology 2001;56:635-642.

33 Chabriat H, Pappata S, Poupon C, Clark CA, Vahedi K, Poupon F, et al: Clinical severity in CADASIL related to ultrastructural damage in white matter: In vivo study with diffusion tensor MRI. Stroke 1999;30:2637-2643.

34 Iannucci G, Dichgans M, Rovaris M, Brüning R, Gasser T, Giacomotti L, et al: Correlations between clinical findings and magnetization transfer imaging metrics of tissue damage in individuals with cerebral autosomal dominant arteriopathy with subcortical infarcts and leukoencephalopathy. Stroke 2001;32:643-648.

35 Ruchoux MM, Maurage CA: CADASIL: Cerebral autosomal dominant arteriopathy with subcortical infarcts and leukoencephalopathy. J Neuropathol Exp Neurol 1997;56:947-964.

36 Dichgans M, Wick M, Gasser T: Cerebrospinal fluid findings in CADASIL. Neurology 1999; 53:233.
37 Weinmaster G: The ins and outs of notch signaling. Mol Cell Neurosci 1997;9:91-102.

38 Artavanis-Tsakonas S, Matsuno K, Fortini ME: Notch signaling. Science 1995;268:225232.

39 Joutel A, Vahedi K, Corpechot C, Troesch A, Chabriat H, Vayssiere C, et al: Strong clustering and stereotyped nature of Notch 3 mutations in CADASIL patients. Lancet 1997;350: 1511-1515.

40 Dichgans M, Ludwig H, Müller-Höcker J, Messerschmidt A, Gasser T: Small in-frame deletions and missense mutations in CADASIL: 3D models predict misfolding of Notch 3 EGFlike repeat domains. Eur J Hum Genet 2000;8: 280-285.

41 Dichgans M, Herzog J, Gasser T: Notch3 inframe deletion involving three cysteine residues causes typical CADASIL (abstract). J Neurol 2001; in press.

42 Liebetrau M, Herzog J, Hamann GF, Dichgans $\mathrm{M}$ : Prolonged cerebral transit time in CADASIL: A transcranial ultrasound study. Stroke 2002, in press.

43 Ruchoux MM, Chabriat H, Bousser MG, Baudrimont M, Tournier-Lasserve E: Presence of ultrastructural arterial lesions in muscle and skin vessels of patients with CADASIL. Stroke 1994;25:2291-2292. 